\title{
Nutritive Potentials of Male and Female Edible Frog (Pelophylax esculentus) II: Selected Trace Elements and Functional Properties
}

\author{
G.O. Oyeleke ${ }^{1}$, M.A. Salam ${ }^{1}$ and R.O. Adetoro ${ }^{2}$ \\ ${ }^{I}$ Science Laboratory Technology Department, Osun State Polytechnic, Iree, Nigeria. \\ ${ }^{2}$ Chemistry Department, Osun State College of Education, Ila-Orangun, Nigeria.
}

\begin{abstract}
Some trace elements; nickel (Ni), lead (Pb), zinc ( $\mathrm{Zn})$, cadmium $(\mathrm{Cd})$, copper $(\mathrm{Cu})$, selenium ( $\mathrm{Se})$, chromium $(\mathrm{Cr})$ and functional properties of meat from male and female edible frog $(E F)$ were determined using standard methods of analysis. The male and female EF contained the following trace elements in $\mu \mathrm{g} / 100 \mathrm{~g} ; \mathrm{Ni}$ (14.75 \pm 0.20 and $12.60 \pm 0.50), \mathrm{Pb}(8.10 \pm 0.05$ and $7.64 \pm 0.02), \mathrm{Zn}(20.15 \pm 0.05$ and $26.20 \pm 0.01), \mathrm{Cr}(4.20$ \pm 0.01 and $4.05 \pm 0.01), C d(0.92 \pm 0.01$ and $0.88 \pm 0.02)$ and $S e(2.84 \pm 0.01$ and $3.25 \pm 0.05)$ respectively. The functional properties (\%) were water absorption capacity WAC (118.20 \pm 0.02 and $125.10 \pm 0.01)$, fat

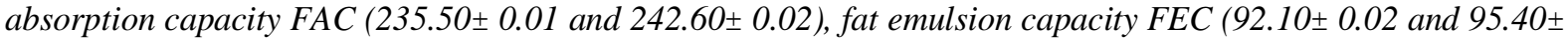
$0.05)$, foaming capacity $F C(34.15 \pm 0.05$ and $37.50 \pm 0.04)$ and least gelation capacity $L G C(12.00 \pm 0.01$ and $11.50 \pm 0.02)$ respectively in male and female $E F$. The results suggest that meat from both male and female $E F$ are safer for consumption due to the concentrations of trace elements compared to the recommended daily allowances (RDA) and would also be useful in other industrial applications especially in food formulation.
\end{abstract}

Key words: Trace, element, edible, frog, functional, food, formulation

\section{Introduction}

Meats are important to human beings and could be obtained from various sources. They are very good source of nutrients and vitamins to the body. Due to high cost of purchase and some health problems associated with common meats, research are now focused on other means of meat that would be cheaper and safer for consumption especially aquatic animals. However heavy metals from man-made pollution sources are continually released into aquatic and terrestrial ecosystems [1].

Oyeleke et al., [2] observed that contamination with heavy metals is a serious threat because of their toxicity and bioaccumulation in the food chain. Tamate, [3]; Zantopoulos et al, [4]; Tahvonen and Kumpulainen, [5]; Mansour and Sidky, [6] had worked on concentrations of heavy metals using different types of meat and fish samples. Heavy elements are natural components of the earth's crust. They cannot be degraded or destroyed. To a small extent, they enter our bodies via food, drinking water and air. As trace elements, some heavy metals at low concentrations are essential to maintain the metabolism of human body, however at higher concentrations, they can lead to poisoning. Heavy metals are dangerous because they tend to accumulate. Bioaccumulation means an increase in the concentration of a chemical in a biological organism over time compared to the chemical's concentration in the environment. Metal occur in varying amounts in rivers, sea and oceans since they are the final repository of soluble elements from the terrestrial part of the planet. Most of these heavy metals have no apparent adverse health effects on the aquatic animals themselves but the risk is to the next level of consumer and in this case; humans.

Functional properties of meat could also be used to assess its value in food industries.

Edible frogs (EF) Pelophylax esculentus (male and female) belongs to the amphibian family and are usually consumed all over the world especially in Nigeria. They inhabit all types of water bodies and feed on invertebrates such as crickets and can also leap for passing insects such as wasps, dragon and hover flies and are therefore atimes referred to as opportunistic feeders. The first part of this research work revealed the importance of male and female edible frog in terms of proximate and mineral components. The aim of this study was to assess the concentration of some heavy elements as well as selected functional properties of meat from male and female EF as no such was found in literature.

\section{Materials and Methods}

\subsection{Materials}

\subsection{Sample collection and Pretreatment}

The dried samples of the EF were purchased from Igbona market, Osogbo, Osun State, Nigeria.

They were sorted out to male and female using size (male are smaller and slimmer to female), presence of nuptial pad (in male only) and length of legs (female legs are longer than male). The sorted samples were washed using demineralized water and dried in an air oven at $60^{\circ} \mathrm{C}$ for $10 \mathrm{~h}$. The fleshy parts of the samples 
Nutritive Potentials Of Male And Female Edible Frog (Pelophylax Esculentus) Ii: Selected Trace (male and female EF) were scrapped using a clean laboratory stainless steel knife, the small pieces were dry milled, kept in air tight polythene bag and stored in a dessicator (with dessicant) prior to further analysis.

\subsection{Methodology}

The trace element content of the samples was determined using the methods of Demirezen and Uruc,

[1] while the functional properties were determined using the methods of Abulude, [7].

The mean and standard deviations were calculated from the duplicate determinations.

\subsection{Results}

\section{Results and Discussion}

Table 1: Trace Elements Determination $(\mu \mathrm{g} / 100 \mathrm{~g})^{*}$

\begin{tabular}{lccc}
\hline Elements & \multicolumn{3}{c}{ Mean \pm S.D } \\
& MEF & FEF & RDA \\
\hline $\mathrm{Ni}$ & $14.75 \pm 0.20$ & $12.60 \pm 1.50$ & $35-700 \mu \mathrm{g} / \mathrm{d}$ \\
$\mathrm{Pb}$ & $8.10 \pm 0.05$ & $7.64 \pm 0.02$ & $210 \mu \mathrm{g} / \mathrm{d}$ \\
$\mathrm{Zn}$ & $20.15 \pm 0.05$ & $26.20 \pm 0.01$ & $8 \mathrm{mg} / \mathrm{d}$ \\
$\mathrm{Cu}$ & $36.27 \pm 0.05$ & $37.12 \pm 0.20$ & $900 \mu \mathrm{gg}-30 \mathrm{mg} / \mathrm{d}$ \\
$\mathrm{Cr}$ & $4.20 \pm 0.01$ & $4.05 \pm 0.01$ & $130 \mu \mathrm{g} / \mathrm{d}$ \\
$\mathrm{Cd}$ & $0.92 \pm 0.01$ & $0.88 \pm 0.02$ & $60 \mu \mathrm{g} / \mathrm{d}$ \\
$\mathrm{Se}$ & $2.84 \pm 0.02$ & $3.25 \pm 0.05$ & $55 \mu \mathrm{g} / \mathrm{d}$ \\
\hline
\end{tabular}

Legend

*Results are average of two (2) determinations \pm S.D

RDA-recommended dietary allowance for $60 \mathrm{~kg}$ adult according to joint expert committee on food additives

(JECFA) provisional tolerable weekly intake (PTWI) and WHO, [8].

MEF- Male edible frog

FEF - Female edible frog.

Table 2: Functional Properties (\%)* of the Male and Female Edible Frog

\begin{tabular}{lcc}
\hline Parameter & MEF \pm S.D & FEF \pm S.D \\
\hline Water absorption capacity (WAC) & $118.20 \pm 0.02$ & $125.10 \pm 0.01$ \\
Fat absorption capacity (FAC) & $235.50 \pm 0.01$ & $242.60 \pm 0.02$ \\
Fat emulsion capacity (FEC) & $92.10 \pm 0.02$ & $95.40 \pm 0.05$ \\
Foaming capacity (FC) & $34.15 \pm 0.05$ & $37.50 \pm 0.04$ \\
Least gelation capacity (LGC) & $12.00 \pm 0.01$ & $11.50 \pm 0.02$ \\
\hline
\end{tabular}

* Average of duplicate determinations $=\mathrm{S} . \mathrm{D}$

\section{Discussion}

From table 1 showing the mean values for the trace elements; Lead $(\mathrm{Pb})$ content in $\mu \mathrm{g} / 100 \mathrm{~g}$ was found to be $8.10 \pm 0.05$ in male and $7.64 \pm 0.02$ in female EF respectively. These values were lower than those obtained for meat by Demirezen and Uruc, [1] but in line with the findings of Zantopoulos et al, [4]. The values obtained here are below the recommended dietary allowance (RDA) of $210 \mu \mathrm{g} / 100 \mathrm{~g} / \mathrm{d}$. High amount of $\mathrm{Pb}$ can lead to cardiovascular disease in human being [2].

Nickel (Ni) content in $\mu \mathrm{g} / 100 \mathrm{~g}$ was $14.75 \pm 0.20$ and $12.60 \pm 1.50$ in male and female EF respectively. These low values make the meat samples useful for children of 1-3 years who required just about $7 \mathrm{mg} / \mathrm{day}$ of $\mathrm{Ni}$.

The copper $(\mathrm{Cu})$ content $(\mu \mathrm{g} / 100 \mathrm{~g})$ was $36.27 \pm 0.50$ in MEF and $37.12 \pm 0.20 \mathrm{in} \mathrm{FEF}$. The values are higher than the range of $(7.18-10.01 \mu \mathrm{g} / 100 \mathrm{~g})$ for meat and $8.12 \mu \mathrm{g} / 100 \mathrm{~g}$ for blue fish [1]. It should be noted that too much intake of $\mathrm{Cu}$ could be injurious to health especially problems associated with kidney.

The other trace element contents of MEF and FEF in $\mu \mathrm{g} / 100 \mathrm{~g}$ are zinc ( $\mathrm{Zn})(20.15 \pm 0.05$ and 26.200 .01 ), chromium (Cr) (4.20 \pm 0.01 and $4.05 \pm 0.01)$, cadmium (Cd) $(0.92 \pm 0.01$ and $0.88 \pm 0.02)$ and selenium (Se) $(2.84 \pm 0.01$ and \pm 0.05$)$. Cr is involved in the functioning of skeletal muscles.

Se contributes to efficiency of the immune system while $\mathrm{Zn}$ is needed for functioning of many enzymes [9]. Values obtained are either lower compared to the limit of RDA and are therefore considered safer for consumption.

It was noted that FEF contain less concentration of these trace elements compared to MEF.

The results obtained for the functional properties (\%) of the male and female EF respectively as obtained in table 2 are water absorption capacity (WAC) (118.20 \pm 0.02 and $125.10 \pm 0.01)$, fat absorption capacity (FAC) $(235.50 \pm 0.01$ and $242.60 \pm 0.02)$, fat emulsion capacity (FEC) $(92.10 \pm 0.02$ and $95.40 \pm$ $0.05)$, foaming capacity (FC) $(34.15 \pm 0.05$ and $37.50 \pm 0.04)$ and least gelation capacity (LGC) $(12.00 \pm 0.01$ 
Nutritive Potentials Of Male And Female Edible Frog (Pelophylax Esculentus) Ii: Selected Trace

and $11.50 \pm 0.02$ ). The low values obtained for least gelation capacity is desirable because it has ability to form a continuous network which exhibits a certain degree of order and this is important because a meal with low value for least gelation is considered a good thickening agent.

The trend of functional properties reported here for both samples were in line with those observed for Adenopus brevriflorus benth seed flour by Oshodi, [10] and Cricket [7]. These values make both the MEF and FEF useful in food processing and formulations such as baking and soup making and could therefore be added to the existing edible meat for human consumption.

\section{Conclusion}

The present research work revealed that both male and female EF meat have lower concentrations of trace elements with favourable functional properties and are therefore safe for consumption.

\section{Acknowledgement}

The authors are grateful to Femi Alabi \& Partners (FAP), Tofa's House, Abuja, Nigeria for contributing to the success of this research work.

\section{References}

[1] D. Demirezen and K. Uruc, Comparative Study of Trace Elements in Certain Fish, Meat and Meat Products. Meat Sci. 74, 2006, $255-260$.

[2] G.O. Oyeleke, D.F. Latona, J.A. Adegbite and R.O. Adetoro, Determination of Heavy Metals in Fish Samples from Selected Dams in Osun State, Nigeria. J. Pure \& Appl. Sci. Vol. 6 Nos. 1 \& 2, 2006, 88-92.

[3] R. Tamate, Distribution, Content and Variation of Minerals in Meat and Meat Products. Jap. J. Dairy \& Food Sci. 36,1987, A1.

[4] N. Zantopoulos, V. Anthoniou and H. Tsoukali, Lead Concentration in Plant and Animal Tissues. J. Environ. Sci. \& Health 6, 1992, 1453-1458.

[5] R. Tahvonen and J. Kumpulainen, Lead and Cadmium Contents in Pork, Beef and Chicken and in Pig and Cow Liver in Finland during 1991. Food Additives \& Contaminants 11,1994, 415-426.

[6] S.A. Mansour and M.W. Sidky, Ecotoxocological Studies. 3. Heavy Metals Contaminating Water and Fish from Fayoum Governorate, Egypt. Food Chemistry 78, 2002, 15-22.

[7] F.O. Abulude, Proximate Composition, Mineral Content and Functional Properties of Cricket (Acheta spp). Pak. J. Sci. Ind. Res. 47(3), 2004, 212-213.

[8] World Health Organisation (WHO), Evaluation of Certain Food Additives and Contaminants. Technical Report Series. 1993, No 837. Geneva.

[9] G.R.K. Niadu, H.O. Denschlag, E. Mauerhofer, N. Porte and T. Balaji, Determination of Macro, Micronutrient and Trace Element Concentrations in India Medicinal and Vegetable Leaves Using Instrumental Neutron Activation Analysis. Applied Radiation and Isotopes. Vol. 50(5), 1999, 947-953.

[10] A.A. Oshodi, Proximate Composition, Nutritionally Valuable Mineral and Functional Properties of Adenopus brevriflorus benth Seed Flour and Protein Concentrate. Food Chem. 45, 1992, 79-83. 